\title{
Reducing Residential Carbon Emissions in Ireland: Challenges and Policy Responses
}

\author{
Gary Goggins, Frances Fahy and Eimear Heaslip
}

\begin{abstract}
Carbon emissions from the residential sector in Ireland are higher than the European average and are rising. This is a concern in a country already struggling to meet its agreed climate targets. In this chapter, the authors highlight key trends that underpin household energy use in Ireland and undertake a critical examination of related energy policy, with particular attention to the role of the consumer. They find a broad objective to place the consumer at the forefront of Ireland's energy transition, but specific detail of how complex social and technical changes will be realised are lacking. The chapter concludes with a case study demonstrating how sustainable energy initiatives can bring together multiple actors with the common aim to address fuel poverty and lower carbon emissions.
\end{abstract}

G. Goggins $(\triangle) \cdot$ F. Fahy · E. Heaslip

School of Geography and Archaeology and Ryan Institute,

National University of Ireland Galway, Galway, Ireland

e-mail: gary.goggins@nuigalway.ie

F. Fahy

e-mail: frances.fahy@nuigalway.ie

E. Heaslip

e-mail: eimear.heaslip@nuigalway.ie

(C) The Author(s) 2019

F. Fahy et al. (eds.), Energy Demand Challenges in Europe, https://doi.org/10.1007/978-3-030-20339-9_5 
Keywords Energy policy • Sustainable consumption - Residential carbon emissions · Ireland · Transition

\section{INTRODUCTION}

Ireland's energy system is heavily reliant on fossil fuels and largely dependent on imports, primarily of oil and gas. The contribution of renewables in the energy mix is significantly behind Ireland's agreed target under EU Directives. Additionally, Ireland has been identified as a European 'laggard' in reducing non-Emission Trading Scheme sector emissions (i.e. emissions associated with energy use in buildings and in transport, and emissions from agriculture). On a macro level, Ireland will need to introduce substantial changes in order to reach emissions targets for 2030 and beyond. This responsibility must be shared across different sectors in society, including the residential sector, which currently accounts for a quarter of all emissions. Indeed, Irish homes on average use more energy and emit substantially more $\mathrm{CO}_{2}$ than their European counterparts (SEAI 2018). There are significant opportunities for reducing household energy use through technological advances, social innovation and changing user practices.

\section{Socio-Material Dynamics of Household ENERgy UsE IN IRELAND}

The residential sector is responsible for $25 \%$ of energy use in Ireland, second only to transport, at $42 \%$ (SEAI 2018). In 2015, the average household in Ireland used 7\% more energy than the EU average and emitted almost $60 \%$ more $\mathrm{CO}_{2}$ than the average EU home (SEAI 2018). Continuing dependency on high-carbon fuels (e.g. oil, coal, peat), falling oil prices and higher incomes are some of the factors that contribute to recent increases in $\mathrm{CO}_{2}$ emissions across the residential sector. In addition, Ireland has experienced a growth in population of $25 \%$ over the period 2000-2016, with upward trends forecast to continue. To accommodate an expanding population, the number of dwellings has also increased to currently stand at 1.7 million households, although this figure remains significantly short of projected housing need, with 
annual average demand estimated to be up to 36,000 units for the next 30 years (IBEC 2018). Yet despite the number of new homes built to ever increasing energy performance standards, the Irish housing stock is among the poorest in Europe in terms of energy efficiency (Goggins et al. 2016). Current trends also show that households are getting bigger, with an average $15 \%$ increase in floor area across all homes between 2000 and 2016 (SEAI 2018). Another contributing factor in residential energy use is the number of persons per household, which for Ireland is the second highest in Europe at 2.7 persons per dwelling (Eurostat 2018).

The location of dwellings can have a significant impact on the type of fuel and heating systems available to households, as some options such as connection to a mains gas network or district-heating system may not be feasible in rural areas. The use of heating oil is particularly dominant in rural households, and the carbon-intensive practice of harvesting and burning peat is socially and culturally engrained in many rural locations. Housing type is also a significant material factor in affecting residential energy use, particularly regarding space heating due to the level of exposed surface area, which is generally greatest for detached houses and lowest for apartments. In Ireland, detached houses make up the vast majority of dwellings in rural areas $(83 \%)$, compared to $19 \%$ in urban locations and $42 \%$ of the overall housing stock. Just $7 \%$ of people in Ireland live in apartments or flats, which is easily the lowest proportion across the EU (Eurostat 2015). While there are clear opportunities for reducing energy use through increasing thermal efficiency of homes, other socially oriented policy instruments such as those that might reduce per capita living area (e.g. encouraging downsizing after children move out) or sharing of resources (e.g. common laundry rooms) can also reduce energy use, but are less developed in Ireland.

\section{Energy Policy in Ireland}

Ireland's energy policy is largely techno-centric, with a strong emphasis on technological change and innovation. For example, improving energy efficiency in the residential sector is considered a critical element of Ireland's energy policy and of a sustainable energy transition, with the Sustainable Energy Authority of Ireland (SEAI) estimating 
a capital investment of the order of $€ 35$ billion over 35 years would be required to make the existing housing stock low carbon by 2050 (SEAI 2017a). Traditionally, Ireland's energy policy was considered the domain of (centralised) Government and utility companies, with other actors (e.g. local authorities; business) largely sidelined, and consumer participation assuming a passive role. However, recent shifts in the framing of the energy challenge have positioned consumers at the forefront of Ireland's energy transition (Mullally et al. 2018).

The most recent government long-term energy policy White Paper sets out a vision to 2030 where Ireland's energy system 'will become more decentralised, altering many traditional assumptions about demand and supply', requiring 'deep change in the mindsets of individual consumers, businesses, agencies, and utility companies' (DCENR 2015: 5). This outlook aligns with the prevailing narrative in European energy policy that a transition to a low-carbon society requires integrated action from a broad range of actors, including householders (Genus et al. 2018). The central role of householders is indirectly elaborated in the White Paper, insofar as it proposes that citizens move from being 'passive consumers' to 'active citizens', and that every citizen has a role to play in the energy transition. Although the paper neglects to define what is understood by 'active citizen', it does state that consumer choice-in the home, in the community, at work and when travelling-is perceived as an important aspect of the energy citizen's role and responsibilities (DCENR 2015). Such a perspective indicates an individualised approach to how energy demand is problematised, with an implied duty upon consumers to make the 'better' energy choices (Genus et al. 2018). While this perspective might evoke traditional problem framings prevalent in EU energy policy around energy efficiency, rational choice and behaviour change, the paper also proposes that 'landowners, neighbours and communities will be able to engage with infrastructure providers and local government to ensure acceptable outcomes for all energy users' and become more engaged in the energy landscape in Ireland (DCENR 2015: 40). Although it is not made explicitly clear how this inherently complex social and technical change might come about, this collective approach acknowledges interactions between various actors as key 
to a sustainable energy transition, thereby presenting opportunities for achieving long-term sustainability goals through changes in complex interactions (Jensen et al. 2018).

\section{Trends in National Household Energy Campaigns in Ireland}

Prominent national energy campaigns are reflective of Ireland's energy policy and associated underlying notions of how, and what kind of, change might come about. Campaigns generally focus on two main areas, encouraging retrofitting of homes and increasing energy awareness, both of which fall under popular problem framings in EU energy policy that prioritise energy efficiency through system optimization, consumer choice and behaviour change (Jensen et al. 2018). For example, the SEAI have run a 'Tips and Advice Campaign' and a 'Be your own energy manager' campaign, focused on providing householders with a series of steps on how to reduce their energy consumption. Recommendations centre around technical innovation and optimization, including using timers with hot water and heating systems, and behavioural changes such as ensuring heating and hot water systems are only switched on as required. Retrofitting is also encouraged, and information campaigns are generally aimed at encouraging householders to avail of significant grants for energy efficiency and renewable energy upgrades. Over recent years, grant aid for households to engage in energy efficiency improvements (e.g. cavity insulation; solar photovoltaic systems) is offered through one of several schemes run by the SEAI. Applications can be made by individual households or as part of a community scheme, with various funding rates available depending on a number of predefined socio-economic and other criteria such as the age of dwelling. The SEAI has also undertaken research into human and psychological factors that influence uptake of such schemes, with a particular focus on encouraging householders to retrofit and the barriers thereof (SEAI 2017b). In total, over 375,000 homes received government grants for energy efficiency improvements between 2000 and 2016.

A review of recent Sustainable Energy Consumption Initiatives (SECIs) in Ireland according to their problem framing reflects the 
Table 5.1 Number of national SECIs according to their problem framing

6. Changes in complex interactions

-4) Changes in everyday life situations

dominance of traditional problem framings that prioritize changes in technology, and changes in individuals' behaviour (Table 5.1). At the same time, there is ample evidence of initiatives that understand the challenge of changing energy use as a more complex and collective concern. These initiatives seek to bring about long-term systemic change by targeting changes in everyday life situations or changes in complex interactions. One such example is the SHARE project, a partnership between sustainable energy organisations working with social housing providers and residents in eight European regions in the UK, Bulgaria, Estonia, France, Germany, Ireland, Slovenia and Sweden.

\section{Case Study: SHARE (Social Housing Action to Reduce Energy Consumption)}

Within an overall context of reducing carbon emissions and reducing the risk of fuel poverty, the SHARE project (2006-2008) aimed to increase awareness of the opportunities and practical options for sustainable energy retrofit and behavioural change. Focusing on existing housing, the project targeted low-income groups located in 10 distinct communities of different scales and sizes. The project was coordinated by the Severn Wye energy agency in the UK, and included eight partners including the Irish-based Tipperary Energy Agency (TEA). 
The TEA engaged with a range of stakeholders in the public and voluntary sector, including householders living in social housing, designers and implementers of social housing, and local authorities that are responsible for the management of social housing in Ireland. The project used several dissemination techniques including training sessions, information provided on the project website, telephone interactions, information stands at Local Authority events and site visits.

\section{Methods for Intervention}

SHARE Forums were set up for each of the eight countries involved to promote good practices and encourage the sharing of experiences. Forums included social housing providers, residents, local authorities, energy providers, building and services contractors, and a variety of specialists working within the sector. Training sessions were undertaken with both the householders and those that are responsible for managing, designing and building social housing. Awareness and advice plans on existing materials and good practices for each participating country were produced and a series of case studies covering the Forums training and awareness campaigns were made available on the project website.

The TEA were responsible for the training sessions in Ireland and concentrated on providing information related to insulation, more energy efficient central heating systems, optimised heating controls, smart metering equipment and renewable technologies where appropriate. Householders were required to attend the training workshops and then attempt to implement some of the recommendations to reduce their energy use and lower energy costs. To assist householders, the project involved face-to-face visits at participants' homes and provided needs-based tailored information and supports (Heiskanen et al. 2018). The SHARE Forums identified some key areas that tenants typically have problems with including understanding energy bills, efficient use of heating and hot water controls, and awareness and management of energy related to electrical appliances and lighting. Other key areas particularly relevant to Ireland included ventilation and condensation, draught proofing, insulation, fuel poverty, options for home heating, renewable energy options, and grants and assistance. 


\section{Framing the Energy Challenge}

As the project focused on low-income households, the TEA primarily focused on framing energy in financial terms, for example 'save on your energy bills'. Broader environmental implications of saving energy were also discussed with participants. Topics of comfort or health related to energy use were not addressed, however these were subsequently recognised as important factors that might be targets for future projects. From the participants' perspective, energy was framed in terms of expensive energy bills, and discussion about the lack of support from government would arise from time to time in the Forums. The implementers reported that trying to focus specifically on energy in social housing presents a challenge, as people have lots of other issues in their lives that they need to deal with, and energy is not often a priority. Hence, one of the challenges was that householders would tend to voice other issues affecting them in the community or housing estate, as they had no other platform in which to voice their concerns.

\section{SHARE Project Impact}

While there were no studies conducted of the environmental or monetary impact of the project, $85 \%$ of participants reported the training to be 'very useful', 15\% found it to be 'fairly useful', with no participant indicating that the training was 'of no use'. The average feedback rating given by 89 participants was 4.5 (out of 5 ). As there was no consumption data recorded, it is difficult to determine whether there were significant, or any, changes in energy use in the long term. However, the project was successful in bringing together a range of actors that influence the consumption of energy in social housing, and promoting collaboration and knowledge exchange between these stakeholders. Although the energy challenge was framed in financial terms, the initiators understood energy use as an outcome of complex interactions between different activities, professions and sectors. The project involved several methods of intervention, and promoted the sharing of responsibility between multiple actors including householders, social housing project designers, implementers and government. 


\section{CONCLUSION}

Ireland has a long way to go in order to meet its binding carbon emissions targets for 2020 and beyond. If Ireland is to meet its longer-term carbon emissions targets, household energy use and related carbon emissions will need to reduce dramatically. This chapter provides examples of recent SECIs undertaken in Ireland. As evidenced in Table 5.1, the majority of these initiatives target changes in individual behaviour or technological changes. These approaches mirror general government policy, where technological and innovation approaches are pursued to provide 'solutions' for problems such as excessive energy use. However, recent trends suggest that technological approaches alone are insufficient to deliver the necessary reductions in residential carbon emissions.

The good practice example illustrates some of the complexities in achieving more sustainable energy use. The SHARE initiative brought together a range of actors from across society, including local authorities, householders and practitioners, to help people in social housing to reduce their energy use and alleviate energy poverty. The tailored approach aimed to overcome some of the contextual difficulties experienced by householders and other actors. However, it also demonstrated the myriad other difficulties facing low-income households, and showed that people are somewhat detached from their energy use. The project also identified some shortcomings in existing SECIs, such as linking energy use with related issues such as comfort, health and well-being, as well as environmental and economic concerns. This more holistic approach to energy use should be considered in designing future initiatives.

\section{REFERENCES}

DCENR. (2015). Ireland's transition to a low carbon energy future 2015-2030. Available at https://www.dccae.gov.ie/documents/Energy\%20White\%20 Paper\%20-\%20Dec\%202015.pdf. Accessed 27 April 2018.

Eurostat. (2015). EU Statistics on Income and Living Conditions (EU-SILC). Available at http://ec.europa.eu/eurostat/statistics-explained/index.php/ Housing_statistics. Accessed 20 November 2018.

Eurostat. (2018). Eurostat labour force survey. Available at https://ec.europa. eu/eurostat/statistics-explained/index.php/Household_composition_statistics\#Household_size. Accessed 20 November 2018. 
Genus, A., Fahy, F., Goggins, G., Iskandarova, M., \& Laakso, S. (2018). Imaginaries and practices: Learning from 'ENERGISE' about the integration of social sciences with the EU Energy Union. In Advancing Energy Policy (pp. 131-144). Cham: Palgrave.

Goggins, J., Moran, P., Armstrong, A., \& Hajdukiewicz, M. (2016). Lifecycle environmental and economic performance of nearly zero energy buildings (NZEB) in Ireland. Energy and Buildings, 116, 622-637.

Heiskanen, E., Laakso, S., Matschoss, K., Backhaus, J., Goggins, G., \& Vadovics, E. (2018). Designing real-world laboratories for the reduction of residential energy use: Articulating theories of change. GAIA-Ecological Perspectives for Science and Society, 27(1), 60-67.

IBEC. (2018). Better housing: Improving affordability and supply.

Jensen, C. L., Goggins, G., Fahy, F., Grealis, E., Vadovics, E., Genus, A., et al. (2018). Towards a practice-theoretical classification of sustainable energy consumption initiatives: Insights from social scientific energy research in 30 European countries. Energy Research \& Social Science, 45, 297-306.

Mullally, G., Dunphy, N., \& O’Connor, P. (2018). Participative environmental policy integration in the Irish energy sector. Environmental Science \& Policy, $83,71-78$.

SEAI. (2017a). Ireland's energy projections: Progress to targets, challenges and impacts. Available at https://www.seai.ie/resources/publications/Irelands_ Energy_Projections.pdf. Accessed 18 April 2018.

SEAI. (2017b). Behavioural insights on energy efficiency in the residential sector. Sustainable Energy Authority of Ireland.

SEAI. (2018). Energy in the residential sector (2018 report). Available at https:// www.seai.ie/resources/publications/Energy-in-the-Residential-Sector-2018Final.pdf. Accessed 2 May 2018. 
Open Access This chapter is licensed under the terms of the Creative Commons Attribution 4.0 International License (http://creativecommons.org/licenses/ by $/ 4.0 /$ ), which permits use, sharing, adaptation, distribution and reproduction in any medium or format, as long as you give appropriate credit to the original author(s) and the source, provide a link to the Creative Commons license and indicate if changes were made.

The images or other third party material in this chapter are included in the chapter's Creative Commons license, unless indicated otherwise in a credit line to the material. If material is not included in the chapter's Creative Commons license and your intended use is not permitted by statutory regulation or exceeds the permitted use, you will need to obtain permission directly from the copyright holder.

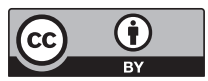

